\title{
ENSINO DE SOCIOLOGIA: O PAPEL DAS GRADUAÇÕES E PÓS- GRADUAÇÕES
}

\section{SOCIOLOGY OF EDUCATION: THE ROLE OF GRADUATIONS AND POSTGRADUATES}

Tânia Elias Magno da Silva ${ }^{1}$

\section{RESUMO}

O objetivo do presente artigo é o de contribuir para o debate sobre o papel das universidades na formação de novos profissionais, em particular, na formação do professor de Sociologia e, em um sentido mais amplo, de Ciências Sociais. Nesse sentido, levanto algumas questões relativas à importância dos cursos de graduação e pós-graduação na formação continuada dos professores de Sociologia.

Palavras Chave: Ensino de Sociologia, Formação Docente, Itinerários da Formação Docente

\section{ABSTRACT}

The purpose of this article is to contribute to the debate on the role of universities in the training of new professionals, in particular in the training of sociology professor and, in a broader sense, of social sciences. In this sense, I raise some questions regarding the importance of undergraduate and postgraduate courses in the continuing education of Sociology teachers.

Key Words: Teaching Sociology, Teacher Training, Teacher Training Itineraries

\footnotetext{
${ }^{1}$ Professora aposentada da UFS, vinculada ao Mestrado e Doutorado em Sociologia do PPGS/UFS.
} 


\section{INTRODUÇÃO}

O objetivo do presente artigo é o de contribuir para o debate sobre o papel das universidades na formação de novos profissionais, em particular, na formação do professor de Sociologia e, em um sentido mais amplo, de Ciências Sociais. Nesse sentido, levanto algumas questões relativas à importância dos cursos de graduação e pós-graduação na formação continuada dos professores de Sociologia. Inicio situando a criação dos primeiros cursos superiores de Ciências Sociais/Sociologia no país e as dificuldades encontradas pelos primeiros professores no que diz respeito à exiguidade de manuais de Sociologia que esses docentes encontravam para subsidiá-los no ensino dessa disciplina. Em seguida, analiso de forma breve as nefastas consequências do Golpe de Estado de 31 de março de 1964 para o ensino no país. Com o decreto do $\mathrm{Al}^{2}$, muitos docentes tanto do ensino superior como do médio e fundamental foram cassados ou considerados "perigosos e subversivos" pelos golpistas, sendo toda uma geração prejudicada pelo banimento de seus mestres e das reformas educacionais que posteriormente foram implantadas. A Sociologia sobreviveu nos cursos de formação de professores primários, o antigo curso Normal, e nos cursos superiores, mas foi sendo abolida paulatinamente no ensino médio, sem que fosse necessário um decreto para retirála do currículo. O resultado dessas "reformas educacionais" foi uma formação escolar menos crítica. Os cursos de Ciências Sociais também foram abalados pelo regime ditatorial, não somente porque houve uma diáspora de seus professores, mas também porque a própria estrutura dos cursos acabou sofrendo modificações hoje questionáveis.

Não me detenho na história da luta para a volta dessa disciplina nos cursos de ensino médio em todo o país ${ }^{3}$, apenas faço algumas referências à aprovação do Decreto que instituiu o retorno das disciplinas de Sociologia e Filosofia nos cursos de ensino médio. Em seguida, levanto algumas questões para o debate trazendo considerações acerca da realidade atual dos cursos de Ciências Sociais/Sociologia

\footnotetext{
${ }^{2}$ Ato Institucional Número 5, decretado em 1968 pelo então General Presidente Garrastazu Médici.

${ }^{3}$ A esse respeito, vide entre outros: Carvalho, Lejeune Mato Grosso Xavier. Sociologia no ensino médio: Mudanças profundas na educação brasileira (2006) - Não publicado.
}

Inter-Legere - Revista de Pós Graduação em Ciências Sociais da UFRN Natal RN, ISSN 1982-1662 no 18, jan./jun. de 2016 p. 190-212 
ENSINO DE SOCIOLOGIA: O PAPEL DAS GRADUAÇŌES E PÓS-GRADUAÇŌES

Tânia Elias Magno da Silva

e da relação entre a licenciatura e o bacharelado, bem como sobre a importância da pós-graduação na formação do professor de Sociologia e a necessidade de se criar e fortalecer em nível de pós-graduação, em todas as IES, linhas de pesquisas que contemplem o mercado de trabalho dos sociólogos e o ensino de Sociologia/Ciências Sociais, buscando cada vez mais melhorar a qualidade desses profissionais. Na conclusão, teço algumas considerações a respeito da fundação e do papel da Associação Brasileira de Ensino de Ciências Sociais (ABECS).

\section{OS PRIMEIROS CURSOS E A PRECARIEDADE DE BIBLIOGRAFIA}

O ensino de Sociologia no Brasil apresenta uma história complexa e marcada em seu início por professores autodidatas ${ }^{4}$, uma vez que o primeiro curso de formação de sociólogos data de 1933, com a fundação da Escola Livre de Sociologia e Política de São Paulo5 . Em 1934, é fundada a Universidade de São Paulo e, em 1939, criada a Faculdade Nacional de Filosofia no Rio de Janeiro. A partir de meados e final da década de 1930, foram surgindo vários Institutos e Faculdades de Filosofia e Ciências Humanas no país e com eles os cursos de Ciências Sociais e/ou Sociologia ${ }^{6}$.

Contudo, a disciplina Sociologia já estava presente nos cursos de Direito antes do surgimento dos cursos de Ciências Sociais ou de Sociologia, bem como já havia na década de 1930 uma série de manuais publicados sobre Sociologia, em especial dirigidos às Escolas Normais, cuja ênfase era servir de instrumental para os futuros professores.

\footnotetext{
4 Vide, entre outros: SILVA, Adriana Elias Magno. Florentino Menezes: um sociólogo brasileiro esquecido. 1997. Dissertação (Mestrado em Sociologia) - Pontifícia Universidade Católica/SP, São Paulo, 1997; MENUCCI, Simone. A institucionalização da Sociologia no Brasil: os primeiros manuais e cursos. 2000. Dissertação (Mestrado em Sociologia) - IFCH, UNICAMP, Campinas, 2000.

${ }^{5}$ Atualmente, Fundação Escola de Sociologia e Política de São Paulo (FESSP/SP), que em maio de 2007 completou 74 anos de existência.

${ }^{6}$ É o caso do Paraná e Minas Gerais, por exemplo. Em 1932, funda-se no Recife a Faculdade de Filosofia e Ciências Sociais, fechada em 1935, para ressurgir com o aparecimento da Universidade Federal. A esse respeito, vide SILVA, Tania Elias M. Josué de Castro: Para uma poética da Fome. Doutorado. Pontifícia Universidade Católica de São Paulo - PUCSP, 1998.
} 
ENSINO DE SOCIOLOGIA: O PAPEL DAS GRADUAÇŌES E PÓS-GRADUAÇŌES

Tânia Elias Magno da Silva

Em seu estudo sobre a história da Sociologia no Brasil, Silva (1997) se detém no estudo de um pioneiro da Sociologia brasileira, o professor sergipano Florentino Menezes, e revela como a falta de manuais para o professor de Sociologia era um grande entrave, de modo que muitos acabavam produzindo seus próprios livros didáticos. Ser cientista social no período que antecedeu a institucionalização da Sociologia enquanto disciplina acadêmica, como afirma a autora, "antes do interesse econômico por uma profissão bem-sucedida, despertava a vontade de vencer desafios em um país ainda imberbe para tal campo" (SILVA, 1997, p. 9).

Em 1931, já como catedrático da cadeira de Sociologia no colégio Atheneu Sergipense, o professor Florentino escreve o Tratado de Sociologia, que passa a ser adotado como livro didático. Ao justificar a elaboração da obra, revela as dificuldades enfrentadas pelos pioneiros:

A ideia da publicação deste livro apareceu, como uma sintese das diversas condições que orientavam a iniciação e o desenvolvimento do curso de Sociologia em Sergipe, no ano de 1929.

Inaugurado este curso, compreendi logo a dificuldade extrema em que se encontravam as minhas alunas que eram apenas tres, as quais não conseguiram, com a urgência necessária para a marcha regular do ensino, o compêndio então exigido pelo regulamento.

Entretanto, esta dificuldade, no atual momento em que escrevo este prefácio, (Dezembro de 1930) não mais existe, pois o notável sociólogo brasileiro Dr. Delgado de Carvalho... resolveu completamente o problema, com a publicação do seu livro Sumário do Curso de Sociologia (MENEZES, 1931, p. 25-26).

Os pioneiros da Sociologia brasileira, na sua maioria autodidatas, enfrentaram enormes dificuldades para ministrar essa disciplina, pois não havia uma referência institucional precisa e sem a qual passavam por enormes adversidades, tais como: falta de material didático e ausência de recursos financeiros que proporcionassem condições adequadas para que os profissionais divulgassem e aprofundassem os estudos e pesquisas que vinham realizando e que foram, de certo, o alicerce do ensino de Sociologia no país.

Menucci (2000), em seu estudo sobre a institucionalização da Sociologia no Brasil, debruça-se exatamente a respeito dos estudos dos primeiros manuais e cursos.

Inter-Legere - Revista de Pós Graduação em Ciências Sociais da UFRN Natal RN, ISSN 1982-1662 no 18, jan./jun. de 2016 p. 190-212 
Com efeito, entre os anos de 1931 e 1945 cerca de duas dezenas de livros didáticos de sociologia foram publicados no Brasil. Eram, pois, livros introdutórios, compêndios, tratados, dicionários, coletâneas de textos e periódicos destinados ao ensino secundário regular, aos cursos de magistério, faculdades e universidades. Trata-se de um conjunto significativo de obras, revelador do estabelecimento de um sistema de difusão do conhecimento sociológico (MENUCCI, 2000, p. 2).

A Sociologia somente ganhou o grau superior das escolas secundárias com a Reforma Campos, Lei 19.890 de 1931, que criou os cursos preparatórios para as faculdades e colocou essa disciplina como obrigatória. Segundo Costa Pinto (1945, p. 25-26), a Sociologia passou a ser fundamental para o ensino com a Revolução de 1930, porque, segundo seus defensores, esta disciplina se encaixava ao espírito e aos princípios em nome dos quais a revolução ascendeu ao poder; era o símbolo de uma formação moderna, voltada para capacitar os futuros dirigentes de um país que se industrializava. Esse era em especial o "espírito" dos fundadores do primeiro curso superior de Sociologia no Brasil, o da Escola Livre de Sociologia e Política de São Paulo.

É importante lembrar que a Escola Livre de Sociologia e Política de São Paulo fundada em 1933, a primeira escola superior de Sociologia do país, tinha como um de seus objetivos atender a demanda para uma classe dirigente, em especial para as necessidades da industrialização, urbanização e modernização de São Paulo, de modo que no currículo do curso dava-se ênfase à administração, ao planejamento e à pesquisa, e não ao ensino.

\section{O OSTRACISMO DA DISCIPLINA}

Até 1969, tanto a Filosofia como a Sociologia ainda faziam parte do currículo de muitas escolas de ensino médio no país, mas após a caça às bruxas decretada pelo Al5, talvez fruto de uma diáspora de mestres, bem como de modificações nos currículos, essas duas disciplinas acabam sendo substituídas por outras, permanecendo apenas nos cursos de Magistério. Sem mercado de trabalho, a 
ENSINO DE SOCIOLOGIA: O PAPEL DAS GRADUAÇŌES E PÓS-GRADUAÇÓES

Tânia Elias Magno da Silva

procura pelo curso de licenciatura na área diminui consideravelmente e a formação do professor de Sociologia vai aos poucos deixando de ser uma preocupação dos cursos de Ciências Sociais/Sociologia. O bacharelado passa a prevalecer em detrimento da licenciatura, que aos poucos foi sendo colocada de lado na maioria das instituições. Em muitas escolas do país, o curso de Ciências Sociais/Sociologia passou a ofertar apenas o bacharelado.

A justificativa para essa escolha era a de que não havia mais mercado de trabalho nessa área e, portanto, demanda. Embora tanto Sociologia como Filosofia fizessem parte da grade dos cursos de Magistério, as duas disciplinas eram, quase sem exceção, ministradas por pedagogos.

A luta pela reintrodução dessas disciplinas nos currículos escolares do ensino médio passou por várias fases e, mesmo sem serem obrigatórias, em muitos estados, como é o caso de São Paulo, Rio Grande do Sul, Paraná, Rio de Janeiro, Minas Gerais, entre outros, foram reintroduzidas no currículo escolar do ensino médio. Contudo, em nível de Brasil, as duas disciplinas continuaram fora do currículo obrigatório, de maneira que os concursos para provimento de vagas para o ensino fundamental e médio não incluíam a disciplina Sociologia ${ }^{7}$.

A luta pela inclusão dessas disciplinas no currículo das escolas de ensino médio em todo o país e a abertura de mercado de trabalho para as centenas de profissionais habilitados para tal somente tiveram êxito no dia 7 de julho de 2006, quando o Conselho Nacional de Educação (CNE), antigo CFE, órgão de Estado, através de sua Câmara de Ensino Básico (CEB), aprovou - por unanimidade de votos - a volta do ensino das disciplinas de Sociologia e Filosofia em todas as 23.561 escolas de ensino médio, públicas e privadas, existentes no Brasil já a partir de $2007^{8}$. No dia 11 de agosto, o ministro da educação Fernando Haddad

\footnotetext{
${ }^{7}$ Não é objeto de reflexão do presente texto a análise da trajetória de luta pela reintrodução de Sociologia na grade curricular dos cursos de ensino médio. A esse respeito, vide, entre outros, Silva (2007).

${ }^{\circ} \mathrm{Na}$ ocasião, foi estabelecido um prazo de um ano para a sua implementação, considerado necessário para que os estados que ainda não adotassem essa decisão pudessem se adequar.
} 
ENSINO DE SOCIOLOGIA: O PAPEL DAS GRADUAÇÕES E PÓS-GRADUAÇÕES

Tânia Elias Magno da Silva

homologou a decisão do CNE, transformada em Resolução 04/06, assinada pela presidente da CEB/CNE, Profa. Dra. Clélia Brandão Alvarenga Peixoto ${ }^{\text {. }}$

\section{A VOLTA DA SOCIOLOGIA NO ENSINO MÉDIO: O PAPEL DAS LICENCIATURAS E DAS PÓS-GRADUAÇÕES}

Reintroduzida nos currículos dos cursos de nível médio em todo o país, como disciplina obrigatória, embora com carga horária muito reduzida, estamos diante de um novo impasse, o que nos leva à necessidade de se repensar os cursos de formação, bem como o papel das pós-graduações na formação e especialização dos professores para o ensino na área de Ciências Sociais/Sociologia, tanto em nível da formação universitária, portanto acadêmica, como em nível de formação de professores para o ensino médio.

Essa questão nos remete à discussão sobre a estrutura e o perfil dos cursos de bacharelado e licenciatura em Ciências Sociais/Sociologia, bem como das pósgraduações: o que há de comum nos diferentes cursos existentes? Qual o objetivo do Projeto Pedagógico desses cursos em relação à formação do professor de Sociologia? Se é que existe um Projeto Pedagógico a orientá-los, fruto de uma discussão ampla com todos os envolvidos, inclusive representantes da sociedade.

Em geral, há em muitos casos uma hierarquia velada nos cursos de Ciências Sociais e/ou Sociologia, atribuindo à licenciatura um status menor em relação ao bacharelado, essa tem sido uma queixa comum feita pelos estudantes e professores de várias instituições do país nos inúmeros fóruns e encontros realizados, nos quais a temática foi colocada. Interessante ressaltar que essa queixa parece estar se invertendo com a criação dos PIBIDs e a abertura de um mercado de trabalho para os licenciados em Ciências Sociais/Sociologia. Parece que a procura pela licenciatura tem superado a do bacharelado e os PIBIDs têm atraído mais

\footnotetext{
${ }^{9}$ Resolução n. 4 de 16 de agosto do CNE, publicada no DOU de 21 de agosto de 2006, Seção 1 , página 
ENSINO DE SOCIOLOGIA: O PAPEL DAS GRADUAÇŌES E PÓS-GRADUAÇÓES

Tânia Elias Magno da Silva

estudantes do que os PIBICs. Essa queixa é o que tenho escutado de muitos colegas em diferentes instituições de ensino ${ }^{10}$.

A respeito do campo de atuação dos sociólogos, e de certo o ensino é um deles, cabe atentar para o que está na Lei que regulamentou a profissão. A Lei que reconhece a profissão de sociólogo ${ }^{11}$ define como tal apenas os bacharéis. Os que possuem apenas licenciatura não são, portanto, sociólogos ao crivo da Lei, mas "professores de sociologia no ensino fundamental e médio". Entretanto, o Decreto Presidencial n. 89.531, de 05 de abril de 1984, que regulamentou a profissão de sociólogo, estabelece, no seu artigo $2^{\circ}$, o qual descreve as atribuições dos sociólogos, em seu item II, que uma das funções do profissional é "ensinar sociologia geral ou específica, nos estabelecimentos de ensino, desde que cumpridas as exigências legais", isto é, que seja licenciado, pois essa é a exigência legal.

De acordo com a Lei que criou a profissão de sociólogo e do Decreto que a regulamentou, é necessário que a pessoa seja bacharel e licenciada para poder gozar de todas as prerrogativas legais, ou seja, ser sociólogo e professor.

Essa dualidade na formação - bacharel e licenciado -, em decorrência de muitas escolas no país terem abolido a licenciatura dos cursos de Ciências Sociais/Sociologia, tem criado situações muito constrangedoras e polêmicas. O outro lado da medalha também é problemático, pois quando o curso oferta tanto o bacharelado como a licenciatura, em geral, as formações estão dissociadas, isto é, o aluno pode optar por uma ou outra formação, havendo, não raro, em muitas escolas, o ingresso separado, ou seja, o aluno é obrigado no primeiro ou segundo semestre a optar por uma das formações e há casos em que o vestibular já é separado. Consequência: os que optam apenas pela licenciatura não serão sociólogos, de acordo com o decreto que regulamentou a profissão, portanto não podem ministrar aulas de Sociologia, embora sejam licenciados. Essa é uma questão que precisa ser enfrentada e resolvida. Apesar dessa controvérsia, apenas licenciados estão

\footnotetext{
${ }^{10}$ Essa questão merece ser mais bem analisada, inclusive demanda um estudo a respeito.

${ }^{11}$ Lei de n. 6.888, de 10 de dezembro de 1980, Portaria Ministerial n. 3230 de 15 de dezembro de 1983 e Decreto Presidencial n. 89.531, de 05Pi de abril de 1984, que regulamentou a profissão de sociólogo.
} 
ENSINO DE SOCIOLOGIA: O PAPEL DAS GRADUAÇÕES E PÓS-GRADUAÇÕES

Tânia Elias Magno da Silva

amparados pela Resolução 02/97 do CNE, que garante ao licenciado, em qualquer área, independentemente de sua formação na graduação em nível de bacharel, que lecione no ensino fundamental e médio, na área de sua licenciatura.

Outra questão a ser discutida diz respeito à valorização das duas formações no âmbito de muitas instituições de ensino superior. Parece haver em algumas instituições de ensino uma valorização menor da licenciatura em relação ao bacharelado, que passa a ser visto tanto pelo corpo docente como pelos alunos como uma formação melhor. A licenciatura seria "o caminho natural" dos alunos considerados mais "fracos" e que não estariam aptos a enfrentar a monografia de conclusão de curso, ou seja, aqueles que "não têm perfil acadêmico", "vocação para pesquisadores", portanto, para a carreira acadêmica.

As questões acima, embora em um primeiro momento pareçam nos remeter a uma discussão apenas sobre os cursos de graduação, estão diretamente vinculadas à formação nas pós-graduações, pois os professores que vão formar os futuros bacharéis/licenciados em Ciências Sociais/Sociologia passam pelas pósgraduações.

Diante dessa realidade, levantam-se algumas questões para o debate, a saber: o ensino de Sociologia tem sido um tema recorrente de preocupação/discussão/pesquisa nas pós-graduações em Ciências Sociais/Sociologia no país? Qual tem sido a produção acadêmica voltada para esse tema nos cursos de Mestrado e Doutorado em Ciências Sociais/Sociologia? Quantos cursos de pós-graduação dispõem de pelo menos uma disciplina voltada para essa área em sua grade? Qual a preocupação dos cursos com a formação do professor de Sociologia?

Creio que um levantamento sobre os temas debatidos e que compõem e compuseram os grupos de trabalho e fóruns nos encontros anuais da Associação Nacional de Pós-Graduação e Pesquisa em Ciências Sociais (ANPOCS), criada em 1977, seria de grande valia para ajudar a responder as questões acima. Outro levantamento que poderá ser feito é junto ao banco de Teses e Dissertações da CAPES nesses últimos vinte anos, para visualizarmos a recorrência de trabalhos sobre o tema, bem como os cursos e as universidades onde os trabalhos foram 
ENSINO DE SOCIOLOGIA: O PAPEL DAS GRADUAÇÕES E PÓS-GRADUAÇÕES

Tânia Elias Magno da Silva

defendidos. É possível também fazer um levantamento das discussões, mesas e fóruns dos Congressos de Sociólogos já realizados, bem como das reuniões da Sociedade Brasileira de Sociologia (SBS).

Outra pesquisa poderia realizar um levantamento na grade de disciplinas das pós-graduações em Sociologia/Ciências Sociais existentes no país para se aquilatar quantas têm em sua grade ou mesmo mantêm núcleos de pesquisa sobre educação. Sabe-se que em várias universidades, nos cursos de pós-graduação, há linhas e grupos de pesquisas voltados para o ensino de Sociologia, como é o caso da UFRN, da UFPR, da UEL, dentre outras, mas é preciso atualizar essas informações e verificar a incidência de trabalhos produzidos. A volta da disciplina ao ensino médio tem fomentado os estudos, mas o que me preocupa é a regularidade e os temas que são trabalhados e, mais ainda, a retomada pelos cursos de Ciências Sociais da valorização de estudos no campo da Sociologia da Educação.

Esse levantamento nos proporcionará um panorama atualizado da situação do ensino de Sociologia nas instituições de nível superior no país, bem como o papel que a pesquisa sobre a formação continuada dos professores de Sociologia vem tendo nos cursos, além de fornecer uma cartografia dos temas que têm dominado a produção acadêmica em nível de pós-graduação em diferentes períodos e o lugar que o ensino de Sociologia vem ocupando nessa produção.

\section{O CAMPO DE TRABALHO DOS SOCIÓLOGOS/PROFESSORES DE SOCIOLOGIA}

Em excelente artigo publicado na Revista Coletiva n. 15 de 2015, o professor Ronaldo Baltar da Universidade Estadual de Londrina (UEL) apresenta de forma sintética uma reflexão sobre o mercado de trabalho para os sociólogos e professores de Sociologia. No artigo, o autor apresenta um quadro acerca das possibilidades de graduação em Ciências Sociais/Sociologia, que formam o sociólogo e/ou o professor de Sociologia, como já mencionamos, uma vez que apenas aos bacharéis é dado o título de sociólogo, enquanto apenas os licenciados podem lecionar no ensino médio, como coloca o articulista: 
Enquanto os licenciados buscam o mercado de trabalho de professores do ensino médio, os bacharéis encontrar-se-ão em um mercado de trabalho mais difuso: o dos profissionais da "Ciência e Intelectuais", segundo a definição da Classificação Brasileira de Ocupações (CBO). Um número menor seguirá a formação acadêmica na pós-graduação stricto sensu (BALTAR, 2015, p. 1).

Embora o número de profissionais pós-graduados que visem o trabalho como professores em Instituições de Ensino Superior (IES) seja mais restrito, a maior parte da carga horária, da estrutura disciplinar e dos incentivos aos alunos dos cursos de Sociologia/Ciências Sociais parece estar voltada para a formação do próprio professor universitário, apesar de essa questão não ser a razão dos cursos. Como afirma Baltar (2015, p. 1): "Acredita-se que, formando o acadêmico de nível superior - o 'pesquisador' -, forma-se também o sociólogo ou o professor de ensino médio, o que não é verdade necessariamente".

Depois de fazer uma análise do campo de trabalho para os sociólogos, inclusive trazendo à tona novas inserções para esse profissional e os embates com outros profissionais que adentraram na seara dos sociólogos, o autor conclui:

O mercado de trabalho para o sociólogo não é favorável aos iniciantes na carreira. De acordo com os dados da Relação Anual de Informações Sociais do Ministério do Trabalho (RAIS/MTE) de 2010, o perfil do profissional contratado tem, em média, acima de 40 anos de idade e mais de 10 anos no emprego. O despreparo com que os jovens sociólogos saem das universidades, em relação ao exercício da profissão, e a falta de estágios efetivamente vinculados ao trabalho profissional do sociólogo são fatores que agravam o problema (BALTAR, 2015, p. 1).

Quanto ao mercado de trabalho para o professor de Sociologia do ensino médio, o autor destaca que essa categoria profissional é bem mais organizada do que os sociólogos, não raro exercendo outras funções e desorganizados enquanto categoria profissional, o que não ocorre com a classe dos professores, pois o perfil do professor está claramente delimitado e o licenciado em Sociologia enquadra-se nesse campo profissional. Contudo, devemos atentar que, 
do ponto de vista salarial, há uma diferença entre escolas públicas e privadas. Para a rede pública, o Ministério da Educação (MEC) estabeleceu, em 2013, um piso salarial de $R \$ 1.567,00$. Vários estados não cumprem o piso estabelecido pelo MEC, motivo de mobilização constante da categoria em todo o Brasil (BALTAR, 2015, p. 1).

Outra demanda, no caso dos professores de Sociologia, é a exígua carga horária semanal, de 1 ou 2 horas apenas.

Trabalhando com dados de 2008, o artigo reforça uma questão que ainda era pertinente em 2015 e que afeta igualmente os professores de Sociologia e os sociólogos em relação à reserva do mercado de trabalho, qual seja, o campo de atuação no ensino também é marcado pela presença de outros profissionais no lugar dos licenciados em Ciências Sociais/Sociologia.

No mesmo estudo da CAPES de 2008, verificou-se que apenas 2.499 (pouco mais de 12\%) dos 20.339 professores de Sociologia eram, de fato, formados em Sociologia ou Ciências Sociais.

Entre 2003 e 2008, a CAPES constatou que foram formados aproximadamente 14 mil licenciados em Ciências Sociais/Sociologia no Brasil. Nesse ritmo, se não houvesse nenhum aumento do número de turmas, seriam necessários mais de 30 anos para cobrir o déficit de docentes em 2008, sem contar os 18 mil docentes de outras áreas que ministravam turmas de Sociologia (BALTAR, 2015, p. 1).

De acordo com o artigo aqui citado, em 2012, segundo dados do INEP, 89,7\% dos professores que estavam ministrando Sociologia no ensino médio não eram licenciados na área. É importante atentar para o que ressalta Baltar (2015, p. 1):

Em 2012, analisando-se os microdados do Censo Escolar produzido pelo Instituto Nacional de Estudos e Pesquisas Educacionais Anísio Teixeira (INEP), havia 54.654 professores ministrando turmas de Sociologia no ensino básico. Os licenciados na área eram $10,3 \%$ do total. O número de docentes de Sociologia mais do que dobrou entre 2008 e 2012, mas a participação dos licenciados em Ciências Sociais/Sociologia reduziu-se.

Outro dado que merece destaque diz respeito às dez universidades que até o ano de 2012 haviam formado o maior número de professores de Sociologia, sendo 
ENSINO DE SOCIOLOGIA: O PAPEL DAS GRADUAÇŌES E PÓS-GRADUAÇÓES

Tânia Elias Magno da Silva

elas: Universidade Federal do Pará, PUC/Minas Gerais, Universidade Estadual de Vale do Acarau, Universidade Federal Fluminense, Universidade Estadual de Londrina, Universidade do Oeste Paulista, Faculdade de Filosofia, Ciências e Letras de Caruaru, Faculdade de Filosofia de Passos, Universidade Federal do Rio de Janeiro, Universidade de Santa Cruz do Sul. Ainda segundo o estudo realizado por Baltar, os dez estados que ofereciam o maior número de turmas de Sociologia, com professores formados na área, eram o Rio de Janeiro, Pará, Minas Gerais, Paraná, Rio Grande do Sul, Ceará, Santa Catarina e Distrito Federal.

A verdade é que, como expõe Baltar (2015), em termos de formação do sociólogo/professor de Sociologia, é necessária uma profunda reestruturação dos cursos na maioria das universidades brasileiras, para que possam ofertar uma formação adequada tanto para o sociólogo como para o professor de Sociologia.

São necessárias disciplinas voltadas para o perfil da profissão, como pesquisa não acadêmica, análise de dados, planejamento, organização de projetos sociais, entre outros tópicos. Para o bacharel, o estágio profissional deve ser estruturado e acompanhado de perto por profissionais da área, para que se possa apresentar uma alternativa às barreiras para a entrada do jovem sociólogo no mercado profissional. Mais do que isso, é necessário encarar a formação do sociólogo e do professor de Sociologia no Ensino Médio em pé de igualdade com a formação do professor universitário, muito mais incentivada e valorizada pelo sistema acadêmico de avaliações (BALTAR, 2015, p. 3).

\section{A FORMAÇÃO PROFISSIONAL DO SOCIÓLOGO/PROFESSOR DE SOCIOLOGIA: UM OLHAR SOBRE A PÓS-GRADUAÇÃO EM SOCIOLOGIA DA UNIVERSIDADE FEDERAL DE SERGIPE (UFS)}

A título de contribuição ao estudo sobre a formação profissional do sociólogo/professor de Sociologia, apresento um levantamento feito em minha universidade (UFS) no banco de dissertações e teses defendidas, bem como as linhas de pesquisa existentes no mestrado e doutorado em Sociologia. Antes, aponto um breve histórico do curso, que se inicia como especialização em Ciências Sociais, 
ENSINO DE SOCIOLOGIA: O PAPEL DAS GRADUAÇŌES E PÓS-GRADUAÇÓES

Tânia Elias Magno da Silva

(pós-graduação lato sensu), curso que antecedeu a criação do curso de graduação na área.

Em 1990, é criado o primeiro curso de bacharelado e licenciatura em Ciências Sociais de Sergipe na Universidade Federal de Sergipe, que passa a funcionar no primeiro semestre de $1991^{12}$. O curso de Pós-Graduação em Ciências Sociais da UFS é anterior à criação da graduação e data de 1987. Surge como resultado de uma série de discussões entre a Pró-Reitoria de Pós-Graduação e os docentes de várias áreas de ensino, em especial os ligados aos departamentos de Sociologia e Psicologia, Economia, Administração, Direito, Serviço Social e Letras, sobre a necessidade de se investir em uma pós-graduação nessa área, dada a demanda que existia em potencial na instituição, embora a universidade não oferecesse até aquela data o curso de graduação em Ciências Sociais. Na ocasião, havia a defesa, por parte de alguns professores, de que o curso de Ciências Sociais deveria ser apenas em nível de pós-graduação, havendo inclusive a divulgação de que tinha sido instituída no MEC e no Conselho Federal de Educação uma comissão de especialistas para propor o fim dos cursos de graduação na área.

Criado o curso, este foi alocado no Centro de Ciências Sociais Aplicadas, sem nenhum vínculo com o Departamento de Ciências Sociais e com um corpo docente bem eclético, sendo a maioria dos professores oriunda da área de Economia, Serviço Social, Direito, Administração e poucos da área das humanidades e das ciências sociais, pois até então havia poucos docentes com formação stricto sensu em Ciências Sociais.

De 1987 a 1993, caracteriza-se como uma pós-graduação lato sensu, uma especialização em Ciências Sociais, tendo como principal público os próprios professores da instituição de diferentes departamentos e a formação de alunos provenientes das mais diversas graduações. Nesse formato, o Núcleo de PósGraduação e Pesquisa em Ciências Sociais (NPPCS) recebeu uma demanda significativa de professores e estudantes, os quais puderam usufruir desse tipo de formação até que fosse criado o mestrado em 1993.

\footnotetext{
${ }^{12}$ Até a presente data é o único curso de formação em Ciências Sociais do estado de Sergipe, tanto em nível de bacharelado como de licenciatura.
} 
ENSINO DE SOCIOLOGIA: O PAPEL DAS GRADUAÇÕES E PÓS-GRADUAÇÕES

Tânia Elias Magno da Silva

De 1990 a 1995, cerca de 19 monografias de especialização foram defendidas, com uma temática bem variada e eclética, resultado da composição do corpo docente e da abertura do curso lato sensu.

Com a criação do curso de mestrado, este passa a atrair não apenas os professores e alunos da UFS, mas também docentes e discentes provenientes de outras instituições de ensino superior de Sergipe e até de estados vizinhos. A reformulação do curso para pós-graduação stricto sensu (mestrado) trouxe como consequência uma produção científica mais sistematizada e uma formação acadêmica mais qualificada ${ }^{13}$.

O mestrado, além de proporcionar a formação de Grupos de Pesquisas mais estruturados, fomentou o surgimento de novos grupos, assim como dinamizou e diversificou a produção acadêmica. O próprio corpo docente sofreu uma modificação no sentido de adequá-lo às normas exigidas pela CAPES.

Em 1993, surge, na verdade, um novo curso, com outra grade de disciplinas e novas regras, embora os reflexos de sua antiga estrutura ainda caracterizassem 0 perfil dos alunos que ingressavam no mestrado e os temas das dissertações que foram defendidas nesse início da nova fase.

O Programa de Mestrado em Sociologia da Universidade Federal de Sergipe foi reestruturado no ano de 1996, quando sofreu mudanças em suas bases, modificando-se suas linhas de pesquisa, que a partir de então seriam: "Movimentos Sociais e Cidadania", "Cultura, História e Memória Social”, "Comunicação, Economia e Política" e "Formas de Intervenção do Estado".

No período de 1996 a 2000, foram defendidas 14 dissertações de mestrado, mantendo-se ainda o mesmo perfil eclético dos temas do período anterior. Em 2003, foram defendidas 19 dissertações e, no primeiro trimestre de 2005, há a primeira turma de mestrandos do novo curso, ao todo 08 , que defenderam suas dissertações de mestrado.

Em 2002, uma nova proposta de pós-graduação foi submetida à apreciação da CAPES, transformando o curso de Mestrado em Ciências Sociais em Mestrado

\footnotetext{
${ }^{13}$ Dados extraídos do documento apresentado pelo NPPCS para a CAPES com a proposta de $\begin{array}{lllll}\text { criação do } & \text { Doutorado } & & \end{array}$
} 
ENSINO DE SOCIOLOGIA: O PAPEL DAS GRADUAÇÓES E PÓS-GRADUAÇÕES

Tânia Elias Magno da Silva

em Sociologia, com a alteração da área de concentração para Cultura e Cidadania, bem como de suas linhas de pesquisa, que passaram a ser: Etnicidade e Religiosidade; Modernidade, Identidade e Cultura Urbana; Política, Cidadania e Direitos Humanos; Trabalho, Políticas Públicas e Desenvolvimento,

No período de 1995 a 2006, o NPPCS já havia titulado 111 mestres, muitos dos quais integram hoje o corpo docente da UFS, ou de instituições de ensino superior da rede particular do estado e de outros estados da federação. Em 2009, foi realizada a primeira seleção para o curso de doutorado em Sociologia. Na justificativa de criação do curso de doutorado em Sociologia, há referência à formação de professores e pesquisadores para o magistério superior, porém não se verificava na proposta nenhuma disciplina ou linha de pesquisa que contemplasse a formação docente e o mercado de trabalho para os sociólogos e/ou professores.

De 2009 até o final de 2015, o curso havia titulado 98 mestres e 14 doutores, mas somente na última reformulação das linhas de pesquisa do programa ocorrida no segundo semestre de 2015 foi criada uma linha de estudos e pesquisas intitulada Itinerários Intelectuais, Profissão e Mercado de Trabalho, que envolve estudos que buscam compreender, de um lado, os processos de formação dos saber es em suas diversas formas: artística, cultural, científica, e a construção dos itinerários intelectuais que resultaram nessa produção. De outro lado, abrange estudos sobre o desenvolvimento dos grupos profissionais, do sistema de ensino e da educação superior e a organização do mercado de trabalho, abrangendo estudos e pesquisas sobre formação profissional, mercado de trabalho e ensino de Ciências Sociais/Sociologia.

Durante os 21 anos de existência do curso de pós-graduação em Sociologia, tanto em nível lato sensu como stricto sensu, apenas em 2015 houve uma defesa de tese cujo tema se voltou para a reflexão sobre o desenvolvimento do ensino e da pesquisa nas universidades brasileiras e teve como ponto de reflexão o campo de ensino e pesquisas nas ciências sociais, porém não estava voltado para o questionamento da formação do professor e do ensino de Sociologia. Com exceção desse trabalho, não encontramos uma única monografia ou dissertação que 
ENSINO DE SOCIOLOGIA: O PAPEL DAS GRADUAÇÕES E PÓS-GRADUAÇÕES

Tânia Elias Magno da Silva

contemple a discussão sobre ensino de Sociologia, mercado de trabalho do sociólogo/professor ou questões afins.

Os temas dos trabalhos apresentados estão afinados com as linhas de pesquisa do curso e com os estudos realizados pelos grupos e laboratórios de pesquisa que existem no PPGS. Até 2015, antes da última reformulação das linhas de pesquisa do curso, apenas um dos núcleos de estudo e pesquisa vinculado ao mestrado/doutorado, intitulado Itinerários Intelectuais, Imagem e Sociedade, contemplava estudos dessa natureza ao estudar itinerários intelectuais, pesquisando não apenas autores e obras, mas também instituições e sua relevância no cenário sociopolítico cultural, abrindo uma janela para os estudos a respeito da temática.

Esse núcleo tem acompanhado a discussão não somente da formação profissional, mas também dos novos perfis que se delineiam nas instituições de nível superior do país a partir das políticas implementadas pelo Ministério da Educação na pontuação docente. Nesse sentido, tem produzido estudos relativos à história da Sociologia no Brasil e na América Latina, estando engajado em nível nacional, desde o início da formação do grupo de estudos sobre o ensino da Sociologia criado pela SBS e a criação da Associação Brasileira de Ensino de Ciências Sociais (ABECS), em 2012, bem como tem apresentado publicações acerca do tema, embora esse esforço não tenha resultado ainda em nenhuma dissertação de mestrado, pois os alunos que ingressam no curso, oriundos da graduação em Ciências Sociais, não possuem a formação profissional como um tema a ser investigado, portanto não houve essa demanda até o presente. Em 2014, o I Congresso da ABECS foi realizado na UFS, nas dependências do Colégio de Aplicação, graças à mobilização desse núcleo de estudos.

Interessante e ilustrativo registrar que, como esse não tem sido um tema recorrente nas monografias de graduação do curso de Ciências Sociais da UFS, houve apenas, até hoje (o curso é de 1981), uma monografia defendida sobre o ensino de Sociologia em 2007 e a aluna, conforme soubemos por sua orientadora, 
ENSINO DE SOCIOLOGIA: O PAPEL DAS GRADUAÇÓES E PÓS-GRADUAÇÓES

Tânia Elias Magno da Silva

teve dificuldades de encontrar um professor interessado pelo tema no Departamento de Ciências Sociais ${ }^{14}$.

Atualmente, o curso de pós-graduação em Sociologia possui 05 linhas de pesquisa: Cidades, Patrimônio e Turismo; Sociologia da Economia, do Desenvolvimento e da Técnica; Itinerários Intelectuais, Profissão e Mercado de Trabalho; Instituições, Movimentos Sociais e Políticas Públicas e Minorias Sociais: Processos Identitários, Dominação, Desigualdade e Resistência.

A criação do curso de Ciências Sociais em nível de bacharelado e licenciatura e a implantação do programa de pós-graduação em nível de mestrado em Sociologia e em seguida de doutorado foram passos decisivos para a consolidação da Sociologia como uma área de conhecimento importante no estado, bem como tem sido responsável por ampliar cada vez mais o espaço de reconhecimento dessa disciplina junto à sociedade sergipana. O reflexo dessa importância e do papel que os formados na área têm exercido pode ser constatado no último concurso público realizado em janeiro de 2004, pelo Governo do Estado, para provimento de vagas no cargo de professor de educação básica do estado de Sergipe, que, a partir de uma mobilização dos licenciados em Ciências Sociais e pressionado pelo Sindicato dos Trabalhadores na Educação de Sergipe (SINTE/SE), incluiu essa disciplina no concurso.

\section{CONCLUSÕES}

A volta da disciplina Sociologia ao ensino médio deverá fomentar uma discussão sobre a formação profissional dos sociólogos/professores de Sociologia, em especial os que seguirem a carreira de professores de Sociologia no referido nível de formação, ou seja, das licenciaturas, mas não somente, também dos bacharelados que formam os sociólogos, pois há grandes transformações no

\footnotetext{
${ }^{14}$ Cabe esclarecer que a disciplina Sociologia da Educação presente na grade curricular do curso de Ciências Sociais da UFS é optativa e foi durante anos ministrada por uma docente formada em Letras e pós-graduada (mestrado e doutorado) em Educação e Filosofia da Educação. Com a aposentadoria dessa professora, a disciplina ficou sob a responsabilidade de outra docente que já a havia ministrado, formada em Serviço Social, mestra em Geografia e doutora em Geografia. No departamento de Sociologia, quase a totalidade dos professores não é licenciada.
} 
ENSINO DE SOCIOLOGIA: O PAPEL DAS GRADUAÇÓES E PÓS-GRADUAÇÕES

Tânia Elias Magno da Silva

mercado de trabalho que exigem um profissional preparado para novas funções e que demandam bons profissionais.

De antemão, já nos vemos diante de alguns desafios, como é caso das Orientações Curriculares de Sociologia, as OCN, que deverão nortear as diretrizes para ensino de Sociologia nas escolas do país. Embora já tenham sido elaboradas e estejam em vigor, há propostas para serem discutidas, contudo o tema não está presente nas principais pautas dos encontros da categoria, nem em nível de graduação nem de pós-graduação.

A verdade é que pouco nos conhecemos enquanto profissionais que formam outros profissionais (assim como pouco conhecemos os docentes que atuam cotidianamente nas escolas da educação básica), uma vez que, não raro, nos ilhamos em nossos laboratórios de pesquisa e o diálogo travado é retórico e preocupado com a pontuação curricular exigida pelos órgãos de fomento. Essa questão também diz respeito a nossa publicação, pois há temas da moda e temas fora de moda, há temas que dão IBOPE e aqueles que poucos consideram importantes; ainda, há uma sociologia do cânone a balizar toda essa questão para a qual a formação profissional e o ensino de Sociologia, em especial no ensino médio, não estão presentes.

Creio que temos que retomar o fio que foi rompido há quarenta anos e que colocou a licenciatura em Ciências Sociais em um segundo plano, bem como todos aqueles que a ela se dedicaram, seja como professor, seja como pesquisador. As questões relativas ao ensino da Sociologia foram transferidas para a alçada dos pedagogos e dos pesquisadores em educação, de modo que a disciplina prática de ensino em ciências sociais passou em muitas universidades a ser alocada no departamento de educação e, não raro, ministrada por um docente desvinculado do curso de Ciências Sociais, mesmo que formado na área. Essa é uma questão também que parece que vem sendo rediscutida em várias universidades, ao menos na UFS há discussões a esse respeito.

São inúmeras as questões a serem levantadas a respeito da formação do professor de Sociologia e do papel das pós-graduações, afinal uma questão que se coloca diz respeito aos múltiplos olhares e interpretações do que seja "formar o 
ENSINO DE SOCIOLOGIA: O PAPEL DAS GRADUAÇÓES E PÓS-GRADUAÇÓES

Tânia Elias Magno da Silva

professor de Sociologia", uma vez que implica pensar o professor para o nível médio de ensino e o professor para o nível superior, enfim, responder uma questão difícil de ser respondida: Qual perfil esse profissional deve ter? Deve haver diferença na formação de um e de outro? Por quê? Qual a responsabilidade dos cursos de pósgraduação na formação desse profissional? Essas questões nos remetem à discussão sobre a visão que se tem do que seja o ensino e do que seja ser professor, tema que pode ser analisado de vários ângulos. Nessa perspectiva, dada a complexidade da questão, não há uma única resposta, mas o importante, creio, é que o debate já se iniciou e a questão está posta.

No ano passado, 2015, a ABECS lançou um Manifesto em Defesa do Ensino Médio no país e da disciplina Sociologia, enviado às autoridades responsáveis pela questão e divulgado nas principais redes sociais, frente à proposta de uma reforma curricular no ensino médio e que colocava em xeque o ensino de Sociologia. Nesse documento, a entidade reafirma seu compromisso na defesa do ensino de Sociologia, na qualidade da formação profissional dos professores de Sociologia e na defesa dessa disciplina nos currículos das escolas de ensino médio em todo o país com uma carga horária similar a outras disciplinas, em face das ameaças que a proposta de reforma curricular em discussão (mais uma) ${ }^{15}$ apontava em relação ao ensino de Sociologia. O Manifesto, produzido e assinado pela diretoria da entidade, iniciava com a seguinte colocação:

Vivemos tempos de intranquilidade com relação às políticas educacionais estaduais e federal para o Ensino Médio, no Brasil que guarda sua origem na orientação de nossas políticas educacionais das últimas duas décadas. A incerteza sobre o que a futura reforma curricular que se anuncia, em nível ministerial, reserva para o destino de nossas escolas, em grande medida resultante de um cenário nebuloso em que decisões são apenas formalmente participativas, tem por fundamento visões repetidas à exaustão, cujo efeito tem sido torná-las verossímeis, até mesmo em círculos intelectuais.

\footnotetext{
${ }^{15}$ Estamos diante de uma nova ameaça feita pelo "novo" governo e pelo atual ministro da educação, que é a retirada da disciplina da grade curricular dos cursos de Ensino Médio, juntamente com Filosofia, Artes Visuais e Educação Física, que ficariam como "optativas" pelas escolas.
}

Inter-Legere - Revista de Pós Graduação em Ciências Sociais da UFRN Natal RN, ISSN 1982-1662 no 18, jan./jun. de 2016 p. 190-212 
O Manifesto faz uma análise da situação do ensino médio em todo o país e tece uma dura crítica às propostas de reformulação dos currículos, sem terem sido consultadas as bases, ou seja, os professores que ministram a disciplina, e às tradicionais maquiagens ditas científicas que envolvem essas propostas. Abaixo cito mais um trecho do documento.

Justificativas à reforma curricular do Ensino Médio brasileiro têm sido há muito divulgadas pela mídia e recebido ornamentações acadêmicas, que Ihes garantem um tom universal - como se universalmente aceitas e razoáveis. No entanto, tais justificativas estão longe de serem consensuais e razoáveis, na exata medida que não oferecem bases sólidas de sustentação. Afirma-se, a exemplo, que "o currículo do Ensino Médio está inchado" e que a quantidade de seus componentes curriculares geram obstáculos à aprendizagem do aluno, mas tais alegações não são acompanhadas de nenhum estudo comparativo ou pesquisa de maior fôlego em que se fixa em bases mais firmes o prejuízo relativo à quantidade de conteúdo e qual a medida justa e por que critério se pode determiná-la; mais que isso, por vezes tal proposição de verdade é feita com base na alegação de que o aluno "não pode gostar da escola com tantos conteúdos a estudar" ou que esse quadro incentivaria a simples "memorização de conteúdos", ainda que tais questões sejam relativas à metodologia, não ao planejamento curricular, e que gostar ou não da escola não esteja em função de quantas e quais disciplinas ela ofereça.

Qualquer que seja a crítica feita à qualidade do ensino nas escolas, é preciso perguntar antes onde e como foram formados os professores? Qual a responsabilidade das instituições de ensino superior que formam o professor para o ensino médio? Qual a responsabilidade dos governos e em especial do governo federal? A essas questões devem ser colocadas também as péssimas condições de trabalho dos docentes que bravamente estão nas escolas de ensino médio do país, ganhando um salário de fome. Não é à toa que a procura pela carreira do magistério tem tido uma baixa significativa em todo o país e algumas áreas de ensino apresentam falta de professores. Igual desistência tem ocorrido com grande número de professores concursados, que desistem muito cedo da profissão.

Entre outras questões, o referido documento chama a atenção para a necessidade de uma reforma curricular e epistemológica das licenciaturas e cursos de formação de professores que, por sua vez, deve estar inserida num contexto de 
ENSINO DE SOCIOLOGIA: O PAPEL DAS GRADUAÇŌES E PÓS-GRADUAÇÓES Tânia Elias Magno da Silva

reforma da instituição universitária como um todo, das relações hierárquicas estabelecidas entre áreas de conhecimento, departamentos e cursos, assim como das relações que a universidade mantém com outras instituições da sociedade.

A defesa do ensino de Sociologia toma como base a colocação feita por Rodrigo Rosistolato ${ }^{16}$ :

Enquanto as outras disciplinas dividem, a Sociologia tende a juntar e por mais que ela tenha muitas especializações e subcampos, a presença de uma Sociologia geral na formação de professores é absolutamente consensual. Se ocorre assim com a formação de professores, por que não ocorreria na formação dos jovens no Ensino Médio? Nós, cientistas sociais, formamos professores de todas as áreas e podemos formar os jovens educandos também, porque se essa formação é tão importante para a educação, que é obrigatória para o docente, por que não o seria para o discente?

É preciso que as universidades assumam também o compromisso de participar dessas discussões que devem envolver não apenas o corpo docente, mas também os futuros professores, portanto, os alunos das licenciaturas e os atuais docentes que estão nas salas de aulas de todo o país; nessa perspectiva, chega de medidas autoritárias de cima para baixo, balizadas por intelectuais de plantão a serviço dos Governos. Faz-se necessário que esse e outros temas estejam presentes no dia a dia da vida universitária, somente assim podemos pensar numa reforma educacional. Este é um tema que diz respeito aos cursos de graduação e de pós-graduação.

\section{REFERÊNCIAS}

BALTAR, Ronaldo. Mercado de Trabalho para os Sociólogos e a Sociologia no Ensino Médio. Revista Coletiva, Recife, n. 15, jan.-abr. 2015.

CARVALHO, Lejeune. Sociologia no ensino médio: mudanças profundas na educação brasileira. São Paulo, 2006.

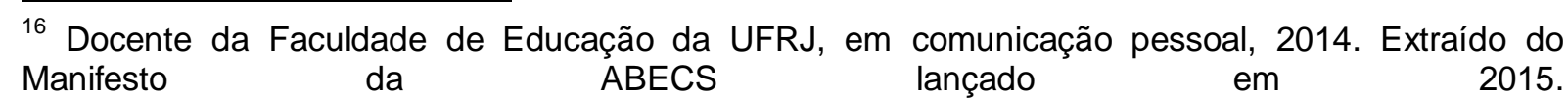


ENSINO DE SOCIOLOGIA: O PAPEL DAS GRADUAÇÓES E PÓS-GRADUAÇÕES

Tânia Elias Magno da Silva

COSTA PINTO, Luiz Aguiar. Ensino de Sociologia nas Escolas Secundárias. Revista de Sociologia, v. 11, n. 3.

FERREIRA, Pinto. Panorama da Sociologia Brasileira I e II. Revista Brasiliense, São Paulo, n. 14, nov./dez. 1957.

MANIFESTO da Associação Brasileira de Ensino de Ciência Sociais. Divulgado em 21 de janeiro de 2015.

MENEZES, Florentino. Tratado de Sociologia. Aracaju: S. N. T., 1931.

MENUCCI, Simone. A institucionalização da Sociologia no Brasil: os primeiros manuais e cursos. 2000. Dissertação (Mestrado em Sociologia) - IFCH, UNICAMP, Campinas, 2000.

SILVA, Adriana Elias Magno. Florentino Menezes: um sociólogo brasileiro esquecido. 1997. Dissertação (Mestrado em Sociologia) - Pontifícia Universidade Católica/SP, São Paulo, 1997.

SILVA, Tânia. A sociologia em Sergipe: um olhar sobre o pioneirismo e a atualidade. In: PLANCHEREL, Alice A.; OLIVEIRA, Evelina A. Leituras sobre Sociologia no Ensino Médio. Maceió: Editora da Universidade Federal de Alagoas, 2007. p. 151173.

SILVA, Tânia. A questão das OCNs: prática pedagógica e formação dos professores de Sociologia: reflexões para o debate. In: SIMPÓSIO AS ORIENTAÇÕES CURRICULARES NACIONAIS - OCN - SOCIOLOGIA, 13. Anais... Recife, 2007.

SILVA, Tânia. Josué de Castro: para uma poética da fome. Revista do Programa Regional de Pós-Graduação em Desenvolvimento e Meio Ambiente PRODEMA, Curitiba, v. 2, n. 1, p. 45-61, jan./jun. 1999. 